\title{
Silymarin-solid dispersions: Characterization and influence of preparation methods on dissolution
}

\author{
DALWADI SONALI ${ }^{1, *}$ \\ SONI TEJAL ${ }^{2}$ \\ THAKKAR VAISHALI ${ }^{2}$ \\ GANDHI TEJAL ${ }^{2}$ \\ ${ }^{1}$ Ramanbhai Patel College of Pharmacy \\ Charotar University of Science and \\ Technology Changa-388421, India \\ 2 Anand Pharmacy College \\ Anand-388001, India
}

Accepted October 25, 2010

\begin{abstract}
The influence of preparation methodology of silymarin solid dispersions using a hydrophilic polymer on the dissolution performance of silymarin was investigated. Silymarin solid dispersions were prepared using HPMC E $15 \mathrm{LV}$ by kneading, spray drying and co-precipitation methods and characterized by FTIR, DSC, XRPD and SEM. Dissolution profiles were compared by statistical and model independent methods. The FTIR and DSC studies revealed weak hydrogen bond formation between the drug and polymer, while XRPD and SEM confirmed the amorphous nature of the drug in co-precipitated solid dispersion. Enhanced dissolution compared to pure drug was found in the following order: co-precipitation $>$ spray drying $>$ kneading methodology $(p<0.05)$. All preparation methods enhanced silymarin dissolution from solid dispersions of different characteristics. The co-precipitation method proved to be best and provided a stable amorphous solid dispersion with 2.5 improved dissolution compared to the pure drug.

Keywords: silymarin, HPMC, solid dispersions, kneading, spray drying, co-precipitation, dissolution parameters
\end{abstract}

Seeds of milk thistle (Silybum marianum L. Gaertn, Asteraceae) have been used in medicine for over 2,000 years. Silymarin (SLM), an antihepatotoxic phytocomplex, is a mixture of flavonolignans which has been widely used as a therapeutic agent for a variety of acute and chronic liver diseases. Silymarin is practically insoluble in water; therefore, upon oral administration, its absorption rate in the gastrointestinal tract is low, providing only about 20 to $40 \%$ bioavailability (1).

Several approaches have been attempted to improve oral bioavailability of silymarin, complexation with a phospholipid (2), formation of an inclusion complex with $\beta$-cyclodextrin and hydroxypropyl- $\beta$-cyclodextrin (3), solid dispersion with a hydrophilic polymer such as PEG 6000 (4), selfmicroemulsifying systems (5), co-precipitates (6) and a complex with crosslinked polymers (7).

\footnotetext{
* Correspondence; e-mail: sonali.dalwadi@yahoo.com
} 
Solid dispersions describe a family of dosage forms whereby the drug is dispersed in a biologically inert matrix of carriers such as polyethyleneglycol (PEG), polyvinylpyrrolidone (PVP), hydroxypropyl methylcellulose (HPMC), crosslinked polymers, usually with a view to enhance oral bioavailability (8). Cellulose derivatives are naturally occurring polysaccharides ubiquitous in the plant kingdom (8). Hypromellose, short for HPMC, is found in a variety of commercial products as an excipient for various purposes (8). In the present study, HPMC, E 15LV was chosen as a polymeric carrier to improve dissolution and bioavailability of several poorly soluble drugs such as carbamazepine (9), cetirizine hydrochloride (10) and felodipin (11).

The aim of the present investigation was to enhance the rate of dissolution of silymarin from solid dispersions and to assess the effect of preparation methodologies on the dissolution performance of solid dispersion.

\section{EXPERIMENTAL}

\section{Materials}

Silymarin powder (containing $78.7 \%$ silymarin, $20.3 \%$ silybin and isosilybin by HPLC) was a gift of Microlabs (India), HPMC E 15LV grade was a gift of Colorcon India, and methanol and dichloromethane AR grade were purchased from Atul Chemical, India. All other ingredients, solvents and reagents used were of analytical or pharmaceutical grade. Deionized double-distilled water was used throughout the study.

\section{Solubility of silymarin}

Solubility studies were performed by placing an excess amount of silymarin into 25-mL glass flasks containing HPMC E $15 \mathrm{LV}$ in $20 \mathrm{~mL}$ distilled water $(0,0.5,1.0,1.5,2.0$, $2.5,3.0,3.5,4.0$ and $5.0 \%(\mathrm{~m} / \mathrm{V}))$. All flasks were stoppered and kept shaking at $100 \mathrm{rpm}$ for $24 \mathrm{~h}$ in an Orbital Shaking Incubator (REMI, RIS24BL, India) at $37^{\circ} \mathrm{C}$. After equilibrium was achieved after $72 \mathrm{~h}, 5 \mathrm{~mL}$ of supernant was withdrawn, filtered through Whatmann filter paper (No. 1) and analyzed using a UV-visible spectrophotometer (Shimadzu UV-1650, Japan) at $286 \mathrm{~nm}$ (3). Experiments were performed in triplicate.

\section{Preparation of physical mixtures}

Physical mixtures of silymarin and HPMC E 15LV in 1:1, 1:3 and 1:5 mass ratios were prepared by mixing in geometric proportions, followed by passing through a $0.152-\mathrm{mm}$ aperture sieve with minimum abrasion. The samples were collected and kept at room temperature in screw-capped glass vials until use.

\section{Preparation of solid dispersions}

Solid dispersions were prepared in 1:1, 1:3 and 1:5 mass ratios of silymarin to HPMC E 15LV by various methods. 
Kneading method. - Silymarin and HPMC E $15 \mathrm{LV}$ were physically mixed, wetted with water and kneaded thoroughly for 30 minutes in a glass mortar. The paste formed was dried completely at $80^{\circ} \mathrm{C}$ for $6 \mathrm{~h}$, pulverized and passed through a $0.152-\mathrm{mm}$ aperture sieve with minimum abrasion. The samples were collected and kept at room temperature in screw-capped glass vials until use.

Spray drying method. - HPMC E 15LV was dissolved in methanol/dichloromethane $(50: 50, V / V)$ and silymarin was incorporated to get $5 \%(\mathrm{~m} / \mathrm{V})$ of total solids in the solution. The resultant solution was evaporated using a Lab Spray Dryer (LABULTIMA, LU-222 Advanced, India) at inlet temperature of $80^{\circ} \mathrm{C}$, maximum aspiration (99), pumping $45 \%$ and feeding rate of $2.5 \mathrm{~mL} \mathrm{~min}^{-1}$ of HPMC E $15 \mathrm{LV}$ solution. The samples were collected and kept at room temperature in screw-capped glass vials until use.

Co-precipitation method. - HPMC E 15LV was completely dissolved in methanol to get $5 \%(\mathrm{~m} / \mathrm{V})$ solution. Silymarin was incorporated, the solution stirred till a homogeneous mixture was formed. Water (in double methanol quantity) was added dropwise to form the precipitate. Dispersion was stirred continuously up to $30 \mathrm{~min}$. Dispersion obtained was dried completely at $80{ }^{\circ} \mathrm{C}$ for $6 \mathrm{~h}$, pulverized and passed through a $0.152-\mathrm{mm}$ aperture sieve with minimum abrasion. The samples were collected and kept at room temperature in screw-capped glass vial until use.

\section{Characterization of solid dispersions}

Characterization was performed for pure silymarin, pure HPMC E 15LV, physical mixtures and solid dispersions prepared by kneading, spray drying and co-precipitation.

FTIR spectroscopy. - IR-spectroscopy was conducted using a FTIR spectrophotometer (Spectrum GX-FT-IR, Perkin Elmer, USA) and the spectra were recorded in the wavelength region of $4000-400 \mathrm{~cm}^{-1}$. The procedure consisted of dispersing the samples in $\mathrm{KBr}$ and gentle grinding to prepare pellets.

Differential scanning calorimetry (DSC). - DSC was performed using a differential scanning calorimeter (DSC-PYRIS-1, Phillips, the Netherlands) to study the thermal behaviour of samples. The samples were heated in hermetically sealed aluminium pans at a scanning rate of $10{ }^{\circ} \mathrm{C} \mathrm{min}$ m $^{-1}$ from $50 \pm 0.2$ to $550 \pm 0.2{ }^{\circ} \mathrm{C}$. An empty aluminium pan was used as a reference.

$X$-ray powder diffraction (XRPD). - X-ray diffraction study was carried out to characterize the physical form of silymarin in selected samples. The sample was allowed to spread on the glass slide in approximately $0.5 \mathrm{~mm}$ thickness. The slide was then placed vertically at $0^{\circ}$ angle in the X-ray diffractometer (X"Pert Model, Philips) so that the X-ray beam fell on it. The results were recorded over a range of $0-90^{\circ}(2 \theta)$ using a Cu-target $X$-ray tube and Xe-filled detector. The conditions were: voltage $40 \mathrm{kV}$, current $20 \mathrm{~mA}$, room temperature, scintillation counter detector, non-rotating sample holder.

Scanning electron microscopy (SEM). - Surface characteristics of the samples were studied by SEM from 100 to 650x magnifications. A double sided carbon tape was affixed onto aluminium stubs. The powder sample was sprinkled onto the tape. The aluminium 
D. Sonali et al.: Silymarin-solid dispersions: Characterization and influence of preparation methods on dissolution, Acta Pharm. 60 (2010) 427-443.

stubs were placed in the vacuum chamber of a scanning electron microscope (XL 30 ESEM with EDAX, Philips). The samples were observed for morphological characteristics using a gaseous secondary electron detector (XL 30, Philips) with working pressure of $0.8 \mathrm{~Pa}$ and acceleration voltage of $30.00 \mathrm{kV}$.

\section{In vitro dissolution study}

The in vitro dissolution studies were carried using USP II (12) apparatus in $900 \mathrm{~mL}$ of distilled water, $0.1 \mathrm{~mol} \mathrm{~L}^{-1} \mathrm{HCl}$ and phosphate buffer $\mathrm{pH}$ 6.8, thermostatically maintained at $37 \pm 0.5{ }^{\circ} \mathrm{C}$ at a rotation speed of $50 \mathrm{rpm}$. Silymarin, all solid dispersions and physical mixtures, each containing an equivalent of $70 \mathrm{mg}$ of silymarin, were subjected to dissolution. At predetermined time intervals, $5 \mathrm{~mL}$ of dissolution medium was withdrawn and filtered through Whatmann filter paper (No. 1). The same volume was replaced with fresh medium. Samples were suitably diluted and analyzed spectrophotometrically at $286 \mathrm{~nm}$. Each test was performed in triplicate.

\section{Dissolution parameters}

Dissolution efficiency (\%). - Dissolution efficiency (DE) represents the area under the dissolution curve at time $t$ (measured using the trapezoidal rule) and expressed as percentage of the area of the rectangle described by $100 \%$ dissolution in the same time (13):

$$
D E=\int_{0}^{t} \frac{y \times \mathrm{d} t}{\mathrm{y}_{100} \times t} \times 100 \%
$$

where $y$ is the drug percent dissolved at time $t$.

Mean dissolution time (MDT). - The MDT values (in min) were calculated from dissolution data using the equation:

$$
M D T=\frac{\sum_{j=1}^{n} \hat{t}_{j} \Delta M_{j}}{\sum_{j=1}^{n} \Delta M_{j}}
$$

where $j$ is the sample number, $n$ is the number of dissolution sample times, $\hat{t}_{j}$ is the time at midpoint between $t_{j}$ and $t_{j-1}$ [easily calculated with the expression $\left(t_{j}+t_{j-1}\right) / 2$ ] and $\Delta M_{j}$ is the additional amount of drug dissolved between $t_{j}$ and $t_{j-1}(13)$.

Similarity factor $f_{2}$ and dissimilarity factor $f_{1}$. - A model-independent approach proposed by Moore and Flanner (14) for calculating $f_{1}$ and $f_{2}$ was used for comparison of the dissolution profiles of various samples and was defined by the following equations: 


$$
\begin{gathered}
f_{1}=\frac{\sum_{j=1}^{n}\left|R_{j}-T_{j}\right|}{\sum_{j=1}^{n} R_{j}} \times 100 \\
f_{2}=50 \log \left\{\left[1+\left(1 / n \sum_{j=1}^{n}\left|R_{j}-T_{j}\right|^{2}\right)\right]^{-0.5} \times 100\right\}
\end{gathered}
$$

in which $n$ is the number of withdrawal points, $R_{j}$ and $T_{j}$ are the percent of the dissolved reference and test products at each time point $j$.

\section{Stability}

Stability of solid dispersions was tested at $40 \pm 2{ }^{\circ} \mathrm{C}$ and $75 \pm 5 \% \mathrm{RH}$ for a period of 6 months. The samples were withdrawn at intervals of 15, 30, 60, 90 and 180 days and were evaluated for the drug content and in vitro drug release. Percentage drug decomposition and any change in a dissolution profile were evaluated using fit factors $\left(f_{1}\right.$ and $f_{2}$ factors).

\section{RESULTS AND DISCUSSION}

\section{Solubility of silymarin}

In the present investigation, solubility of silymarin in distilled water was found to be $0.25 \pm 0.00_{4} \mathrm{mg} \mathrm{mL}^{-1}$. The solubility plot of silymarin in HPMC E 15LV (see Fig. 1) shows that a 2.7 fold increase in solubility was found in $3 \%$ HPMC E $15 \mathrm{LV}$ compared to solubility in water. As the concentration of HPMC increased from 3 to $5 \%$, silymarin solubility decreased, possibly due to the increase in solution viscosity (8) (Table I).

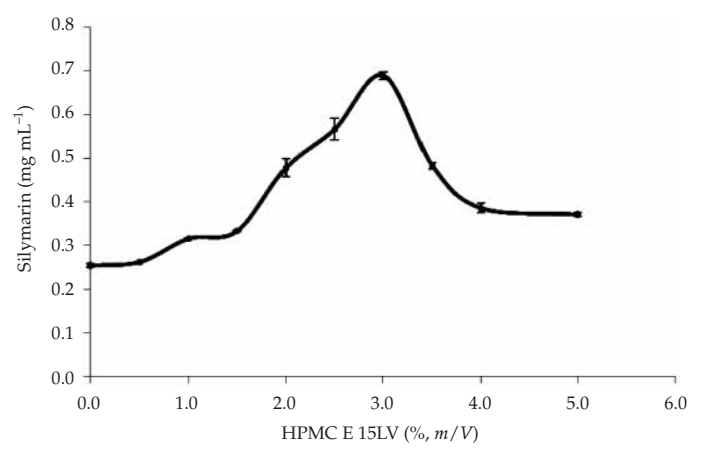

Fig. 1. Solubility plot of silymarin in HPMC E 15LV. 
D. Sonali et al.: Silymarin-solid dispersions: Characterization and influence of preparation methods on dissolution, Acta Pharm. 60 (2010) 427-443.

The values of Gibb's free energy change $\left(\Delta G^{\circ}{ }_{t r}\right)$ were calculated from the following equation to understand the transfer process of silymarin from distilled water to aqueous solution of HPMC E 15LV (15):

$$
\Delta G^{\circ}{ }_{\text {r }}=-2.303 R T \log \left(S_{0} / S_{\mathrm{s}}\right)
$$

in which $S_{0} / S_{\mathrm{s}}$ is the ratio of the molar solubility of silymarin in an aqueous solution of HPMC E 15LV to that in distilled water. The $\Delta G^{\circ}{ }_{t r}$ values were all negative for HPMC E $15 \mathrm{LV}$ at various concentrations (Table I), indicating the spontaneous nature of silymarin solubilization (15).

\section{Characterization of solid dispersions}

FTIR. - It is well known that vibrational changes can serve as a probe of intermolecular interactions in solid materials. Characteristic peaks of silymarin appeared at 3423.36 (-OH stretching vibration), 2935 (O-H stretching), 1639.6 ( $\mathrm{C}=\mathrm{O}$ stretching), 1511-1465 (skeleton vibration of aromatic $\mathrm{C}=\mathrm{C}$ ring stretching), 1362 (-OH in plane bending), 1274.6 (C-O-C stretching), 995 (O-H out plane bending), 1029-1161 (in plane = C-H bending) and $644-849 \mathrm{~cm}^{-1}$ (see Fig. 2) (8). All spectra of solid dispersions showed changes from parent spectra, that is, of silymarin and HPMC. Possible interactions would have occurred between the -OH, C-O, and -O-groups of HPMC E 15LV and of polyphenolic moiety of silymarin revealed through frequency changes of the respective functional group (7).

Table I. Solubility and $\Delta \mathrm{G}^{\circ}{ }_{\text {tr }}$ values of silymarin

\begin{tabular}{ccc}
\hline $\begin{array}{c}\text { HPMC E 15LV } \\
(\%, m / V)\end{array}$ & $\begin{array}{c}\text { Solubility of silymarin } \\
\left(\mathrm{mg} \mathrm{mL}^{-1}\right)^{\mathrm{a}}\end{array}$ & $\begin{array}{c}-\Delta G^{\circ} \\
\left(\mathrm{J} \mathrm{K}^{-1} \mathrm{~mol}^{-1}\right)^{\mathrm{b}}\end{array}$ \\
\hline 0.0 & $0.254 \pm 0.004$ & - \\
0.5 & $0.262 \pm 0.001$ & -83.9 \\
1.0 & $0.316 \pm 0.001$ & -561.2 \\
1.5 & $0.333 \pm 0.002$ & -699.5 \\
2.0 & $0.479 \pm 0.021$ & -1632.3 \\
2.5 & $0.567 \pm 0.025$ & -2069.7 \\
3.0 & $0.689 \pm 0.009$ & -2573.6 \\
3.5 & $0.482 \pm 0.008$ & -1648.2 \\
4.0 & $0.386 \pm 0.011$ & -1075.8 \\
5.0 & $0.371 \pm 0.004$ & -891.4 \\
\hline
\end{tabular}

a Mean $\pm \mathrm{SD}, n=6$.

${ }^{\mathrm{b}} \Delta G_{\mathrm{tr}}^{\circ}-$ Gibb's free energy change 
D. Sonali et al.: Silymarin-solid dispersions: Characterization and influence of preparation methods on dissolution, Acta Pharm. 60 (2010) 427-443.

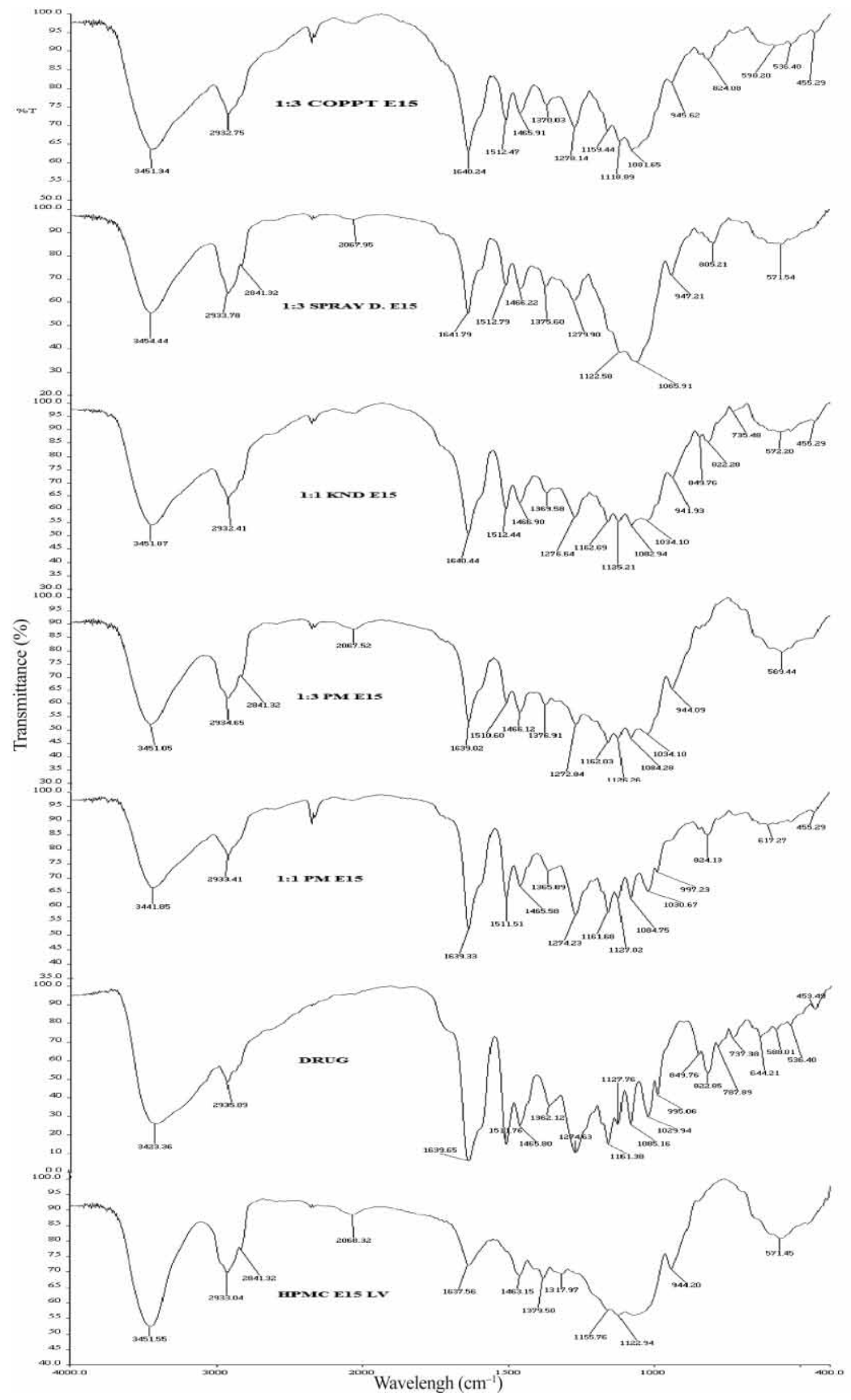

Fig. 2. FTIR spectra of: pure HPMC E 15LV, silymarin, physical mixtures (PM), solid dispersions (KND - kneading, SPRAY D. - spray drying, COPPT - co-precipitation), bottom to top. 
In the spectra of physical mixtures, characteristic peaks substantially corresponded to the superimposition of the peaks of both components, silymarin and HPMC. The band which appeared at $3000-3600 \mathrm{~cm}^{-1}$ (assigned to -OH stretching) in the spectrum of silymarin was found at higher frequency in the case of dispersions. This revealed the formation of $\mathrm{H}$-bond between the drug and $-\mathrm{OH}$ group of HPMC E 15LV in dispersion (14). The characteristic peaks at 1600-1300 and below $1300 \mathrm{~cm}^{-1}$ were found to change their intensity in the following order: co-precipitated $<$ spray-dried $<$ kneaded solid dispersion, but the $\mathrm{H}$-bond interaction which occurred in solid disperions resulted in lower peak intensity $(7,15)$. The IR spectra also demonstrate disruption of the crystal lattice (8). In fact, the splitting phenomenon in frequency regions below $1300 \mathrm{~cm}^{-1}$, a typical feature of the crystal lattice present in silymarin, was still present in physical mixtures, but its intensity was reduced in kneaded, spray-dried and co-precipitated solid dispersions.

DSC. - The DSC thermograms of silymarin, HPMC E 15LV, physical mixtures and solid dispersions are shown in Fig. 3. There was a considerable shift in the endothermic peaks in the kneaded solid dispersion and physical mixture (1:1 ratio). The maximum shifted from $369.7^{\circ} \mathrm{C}$ to $349.2^{\circ} \mathrm{C}$ and $349.9^{\circ} \mathrm{C}$ in thermograms of kneaded solid dispersion and physical mixture, respectively, depicting the change in the crystal form of the drug (17). Due to low silymarin enthalpy $\left(\Delta H=27.280 \mathrm{~J} \mathrm{~g}^{-1}\right)$ found from thermograms, the DSC technique could not be used for characterization of silymarin solid dispersion since suppression and disappearance of peaks could not be identified in the thermogram (Fig. 3).

XRPD. - XRPD pattern of silymarin, HPMC E 15LV, physical mixtures and solid dispersions prepared by different methods are shown in Fig. 4. Silymarin is crystalline, as demonstrated by the sharp and intense diffraction peak at $2 \theta$ of $72.3^{\circ}$. HPMC E 15LV was found as an amorphous powder having no diffraction peak. Physical mixtures showed diffraction peaks consistent with the presence of crystalline silymarin. The lower intensity of diffraction peaks of physical mixtures was the result of a dilution effect with amorphous HPMC E 15LV (18). The intensity of peak height was found to be reduced at $2 \theta=72,3^{\circ}$ in kneaded and spray dried solid dispersions as compared to silymarin. The XRPD pattern of co-precipitated solid dispersion showed complete disappearance of the diffraction peak at the same $2 \theta$ value, confirming the existence of the amorphous form of silymarin.

The relative degree of crystalinity (RDC) of all solid dispersions and physical mixtures at the same $2 \theta$ value are shown in Table II. The rank order of the relative degree of crystallinity in dispersions could be given as: spray dried $>$ kneaded $>$ co-precipitated solid dispersions. Co-precipitation produced amorphous particles compared to the pure drug, which might be responsible for improved dissolution of the drug (19).

SEM. - The representative photomicrographs of silymarin, HPMC E 15LV, physical mixtures and solid dispersions prepared by different methods are presented in Fig. 5. The image of silymarin revealed drug particles with a reduced specific surface area due to some aggregation and agglomeration. Morphological images of HPMC E 15LV exhibited cylindrical shape and similar to fiber (20). The photomicrographs of physical mixtures showed individual particles of silymarin and carrier without any surface adsorption. 
D. Sonali et al.: Silymarin-solid dispersions: Characterization and influence of preparation methods on dissolution, Acta Pharm. 60 (2010) 427-443.

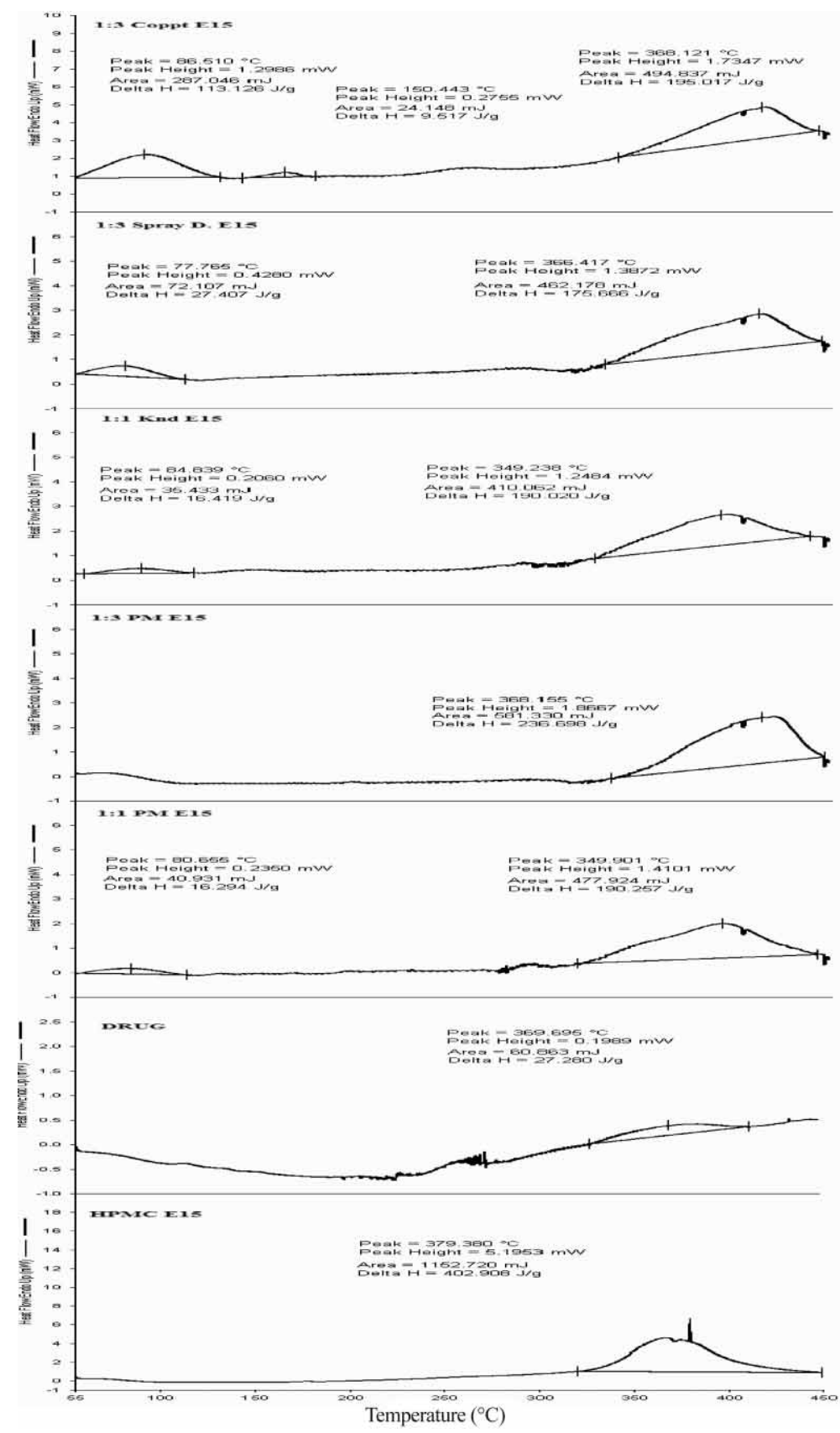

Fig. 3. DSC thermograms of: pure HPMC E 15LV, silymarin, physical mixtures (PM), solid dispersions (KND - kneading, SPRAY D. - spray drying, COPPT - co-precipitation), bottom to top. 
D. Sonali et al.: Silymarin-solid dispersions: Characterization and influence of preparation methods on dissolution, Acta Pharm. 60 (2010) 427-443.

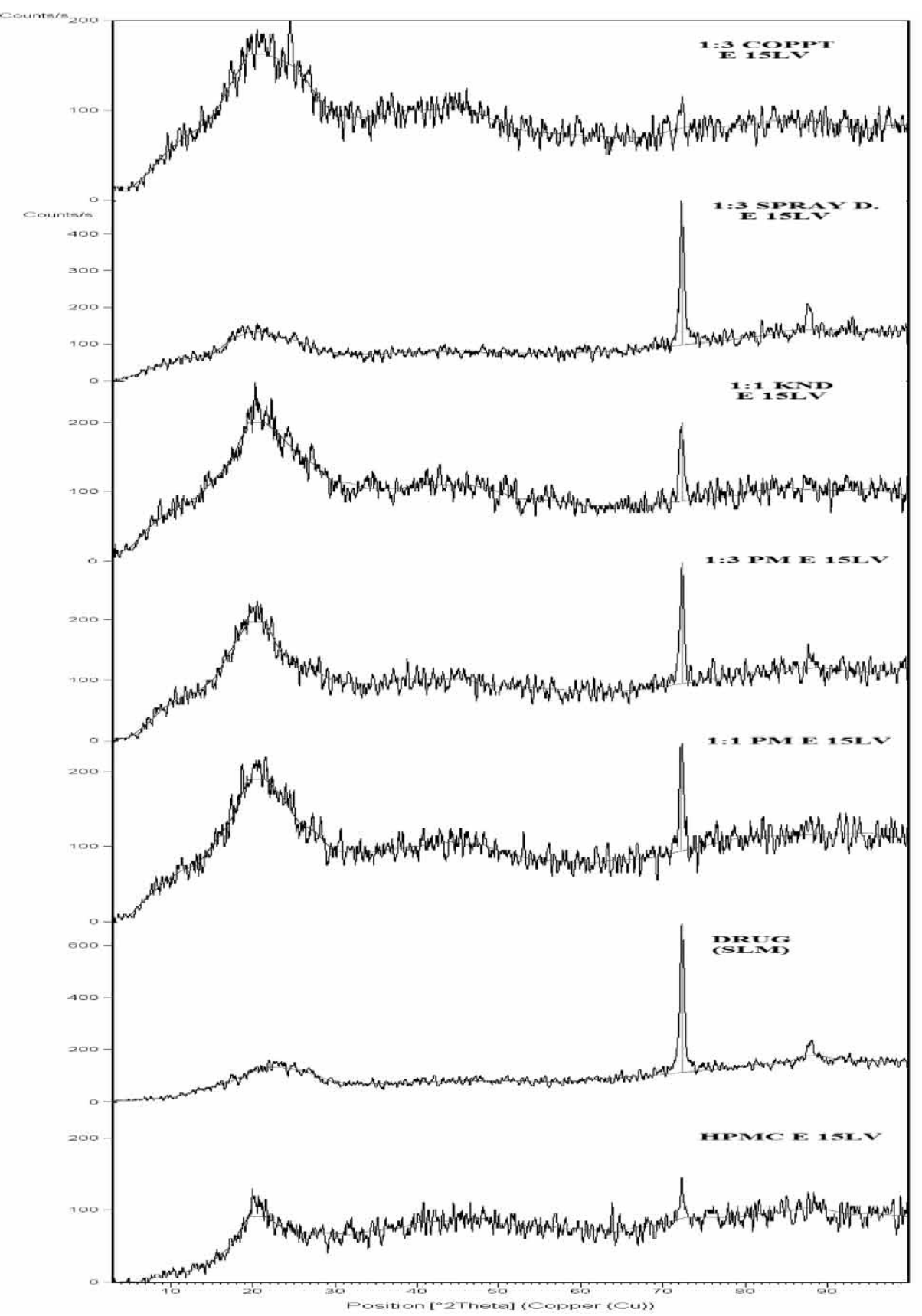

Fig. 4. XRPD patterns of: pure HPMC E 15LV, silymarin, physical mixtures (PM), solid dispersions (KND - kneading, SPRAY D. - spray drying, COPPT - co-precipitation), bottom to top. 
D. Sonali et al:: Silymarin-solid dispersions: Characterization and influence of preparation methods on dissolution, Acta Pharm. 60 (2010) 427-443.

Table II. Relative degree of crystallinity of physical mixtures and solid dispersions

\begin{tabular}{lc}
\hline \multicolumn{1}{c}{ Sample } & Relative degree of crystalinity at $2 \theta=72.3^{\circ}$ \\
\hline Co-precipitation (1:3) & - \\
Spray drying (1:3) & 0.68 \\
Kneading (1:1) & 0.20 \\
Physical mixture (1:3) & 0.35 \\
Physical mixture (1:1) & 0.25 \\
Silymarin & 1.00 \\
HPMC E 15LV & - \\
\hline
\end{tabular}

RDC - relative degree of crystalinity [ratio of the peak height in solid dispersion and the peak height of silymarin alone, at the same angle (11)].

In the case of kneaded solid dispersions, photomicrographs showed that silymarin particles were physically adsorbed over the respective carrier and formed porous solid dispersion particles with a hard surface having crevices and fissures. The morphological

a)

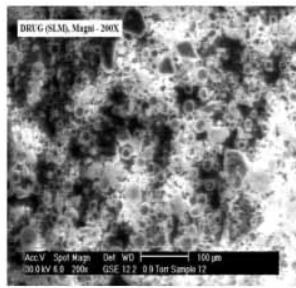

b)
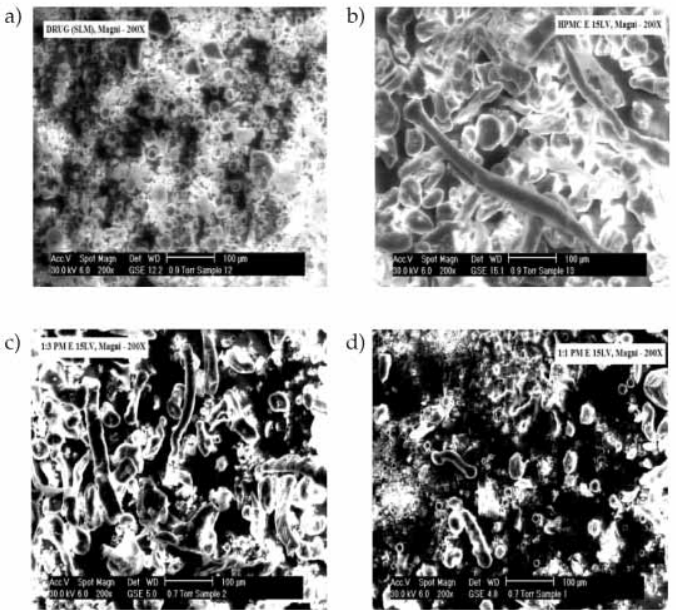
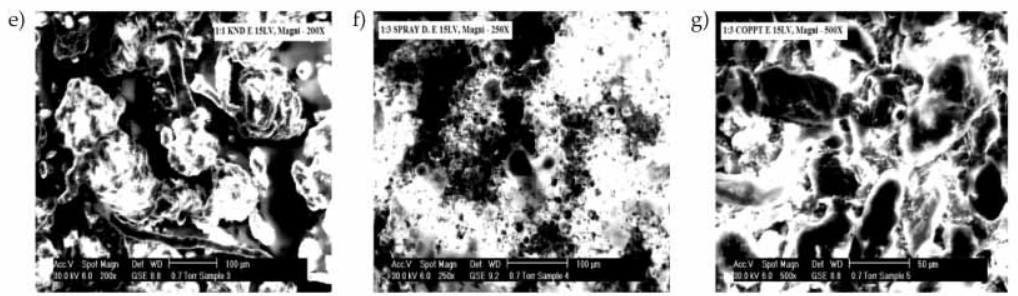

Fig. 5. SEM of: a) drug (SLM), b) HPMC E 15LV, c, d) physical mixtures (1:1, 1:3) and e, f, g) solid dispersions (kneading, spray drying and co-precipitation). 
D. Sonali et al.: Silymarin-solid dispersions: Characterization and influence of preparation methods on dissolution, Acta Pharm. 60 (2010) 427-443.

images of the spray-dried solid dispersion revealed that drug particles were distributed uniformly on the surface of carrier. Therefore, size reduction and uniform adsorption of the drug over carrier were found in solid dispersion prepared by spray drying (21). The SEM photomicrographs of the co-precipitated solid dispersion showed fully amorphous and porous nature with an irregular, coarser and hard surface full of crevices. The images further suggest the existence of an amorphous product with the presence of a single component in the solid dispersion (16).

\section{In vitro dissolution and dissolution parameters}

The in vitro dissolution profiles of pure silymarin, physical mixtures, and optimum ratios in solid dispersions prepared by kneading, spray drying and co-precipitation in distilled water (Fig. 6a), $0.1 \mathrm{~mol} \mathrm{~L}^{-1} \mathrm{HCl}$ (Fig. 6b) and phosphate buffer $\mathrm{pH} 6.8$ (Fig. 6c) over a period of $90 \mathrm{~min}$ are shown. It was evident that the in vitro dissolution of pure silymarin was very low in all dissolution media (drug released after 60 min was 46.8, 45.3 and $43.3 \%$ in water, $0.1 \mathrm{~mol} \mathrm{~L}^{-1} \mathrm{HCl}$ and PBS 6.8, resp.). The kneading, spray drying and co-precipitation methods improved silymarin dissolution within $90 \mathrm{~min}$ in all three dissolution media. Co-precipitation method showed maximum dissolution enhancement as compared to other preparation methods (> $80 \%$ silymarin was released within $10 \mathrm{~min}$ from solid dispersion in three different dissolution media). This suggests that preparation methodology has an effect on drug dissolution improvement.

The drug release from physical mixtures after 10 min was enhanced compared to pure silymarin in all dissolution media.

The value of $D E_{10 \mathrm{~min}}$ for pure silymarin was enhanced in physical mixtures as well as in solid dispersions prepared by different methods significantly $(p<0.05)$ (Table III). Among the different preparation methodologies used, increased in the following order: co-precipitation $>$ spray drying $>$ kneading.

The mean dissolution time $(M D T)$ is a measure of drug release retarding ability of the dosage form (15). The value of $M D T$ in three dissolution media for pure silymarin, physical mixtures and solid dispersions prepared by different methods is presented in

Table III. Dissolution efficiency of solid dispersions prepared by various methods

\begin{tabular}{|c|c|c|c|c|c|c|c|c|c|}
\hline \multirow[b]{3}{*}{ Parameter } & \multicolumn{9}{|c|}{$D E(\%)$ after time (min) } \\
\hline & \multicolumn{3}{|c|}{ Water } & \multicolumn{3}{|c|}{$\mathrm{HCl}\left(c=0.1 \mathrm{~mol} \mathrm{~L}^{-1}\right)$} & \multicolumn{3}{|c|}{ РB pH 6.8} \\
\hline & 10 & 30 & 60 & 10 & 30 & 60 & 10 & 30 & 60 \\
\hline Silymarin & 15.6 & 43.6 & 63.4 & 38.8 & 67.5 & 80.1 & 31.6 & 58.2 & 73.1 \\
\hline Kneading (1:1) & 48.9 & 73.5 & 78.5 & 35.5 & 63.2 & 77.9 & 35.4 & 60.8 & 72.8 \\
\hline Spray drying (1:3) & 37.9 & 67.6 & 81.3 & 37.6 & 65.1 & 76.8 & 37.6 & 65.1 & 76.8 \\
\hline Co-precipitates (1:3) & 44.8 & 77.8 & 87.5 & 43.1 & 76.1 & 87.6 & 42.6 & 74.3 & 86.3 \\
\hline Physical mixture (1:1) & 26.0 & 49.4 & 66 & 36.8 & 62.8 & 72.5 & 39.6 & 67.3 & 79.8 \\
\hline Physical mixture (1:3) & 25.6 & 49 & 65 & 34.8 & 59.8 & 69.6 & 39.0 & 66.6 & 78.6 \\
\hline
\end{tabular}

DE - dissolution efficiency 
D. Sonali et al.: Silymarin-solid dispersions: Characterization and influence of preparation methods on dissolution, Acta Pharm. 60 (2010) 427-443.

a)

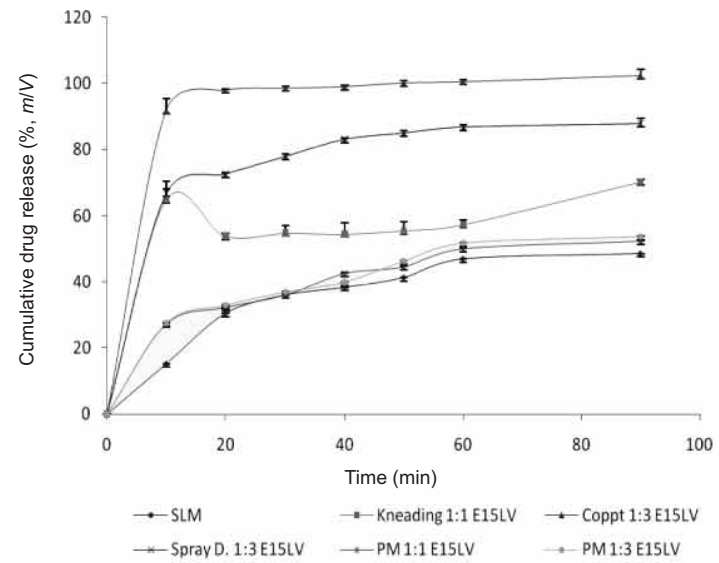

b)

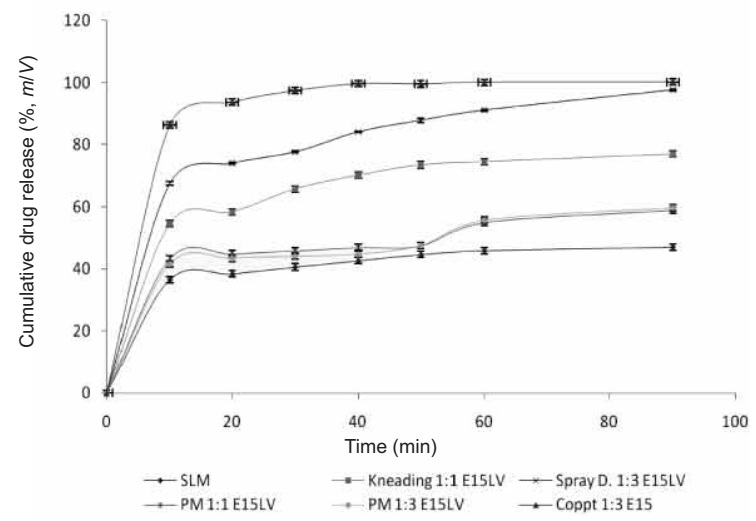

c)

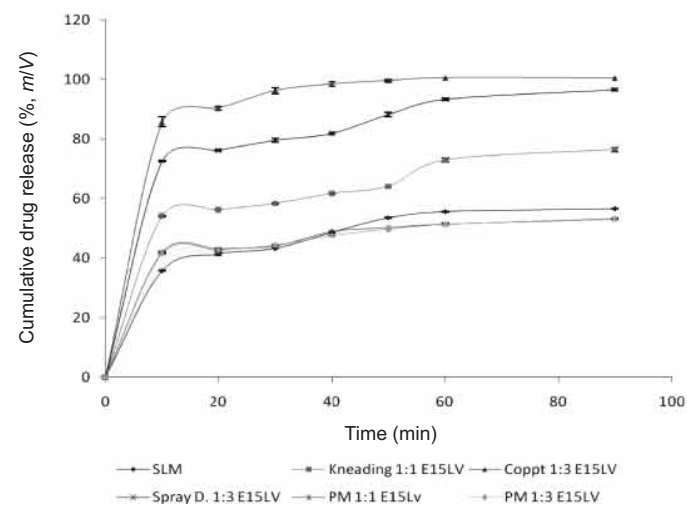

Fig. 6. In vitro dissolution profiles of solid dispersions in: a) water, b) $0.1 \mathrm{~mol} \mathrm{~L}^{-1} \mathrm{HCl}$, c) $\mathrm{PB} \mathrm{pH} 6.8$ (Mean $\pm \mathrm{SD}, n=3$ ). 
D. Sonali et al.: Silymarin-solid dispersions: Characterization and influence of preparation methods on dissolution, Acta Pharm. 60 (2010) 427-443.

Table IV. It is evident that higher silymarin release was obtained ( $M D T=7.4-8.3 \mathrm{~min})$. The MDT value increased from spray drying to kneading. The physical mixtures also showed a considerably lower MDT value compared to pure silymarin.

It is evident from dissimilarity and similarity factors that the release profiles of silymarin prepared by all methods were significantly different (exception: physical mixtures) from that of silymarin (Table IV). Co-precipitation method showed maximum dissimilarity $\left(f_{1}\right.$ value higher than 100) and therefore is the best method to improve dissolution of silymarin in all dissolution media.

Analysis of variance revealed that the drug release profiles of kneaded solid dispersion (1:1 drug to polymer ratio), co-precipitated (1:3 drug to polymer ratio) and spray dried solid dispersion (1:3 drug to polymer ratio) were significantly different $(p<0.05)$ from that of pure silymarin. They showed improved drug release compared to that of pure drug and other ratios of the respective methods. It is evident that in vitro dissolution of silymarin from co-precipitated solid dispersion was also significantly different $(p<0.05)$ from that of pure silymarin and physical mixtures in different dissolution media.

The improved dissolution of silymarin from solid dispersion prepared by kneading, spray drying and co-precipitation was attributed to the solubilizing effect of the carrier. The improvement of powder wettability could result from formation of a gel layer around the drug substance particles modifying the hydrophobicity of surfaces (11). Solid dispersions using HPMC E 15LV became gelatinized in the dissolution media. The gelatinized solid dispersion is constantly crushed by attrition during stirring and the finely gelatinized solid dispersion diffuses to bulk solution through the diffusion layer. Being water retentive, gelatinized dispersion also increases drug wetting, which is attributable to the increase in dissolution (8). In addition, other factors such as increased surface area, the absence of aggregation and agglomeration between hydrophobic drug particles, conversion of drug to the amorphous form and good dispersibility of the dispersed drug might have also contributed to the observed increase in the dissolution rate of silymarin from solid dispersions prepared by different methods (15).

Table IV. Dissolution parameters for solid dispersions prepared by various methods

\begin{tabular}{|c|c|c|c|c|c|c|c|c|c|}
\hline \multirow{2}{*}{$\frac{\begin{array}{l}\text { Dissolution } \\
\text { medium }\end{array}}{\begin{array}{l}\text { Dissolution } \\
\text { parameter }\end{array}}$} & \multicolumn{3}{|c|}{ Water } & \multicolumn{3}{|c|}{$\mathrm{HCl}\left(c=0.1 \mathrm{~mol} \mathrm{~L}^{-1}\right)$} & \multicolumn{3}{|c|}{ PB pH 6.8} \\
\hline & $\begin{array}{l}M D T \\
(\mathrm{~min})\end{array}$ & $f_{1}$ & $f_{2}$ & $\begin{array}{l}M D T \\
(\min )\end{array}$ & $f_{1}$ & $f_{2}$ & $\begin{array}{l}M D T \\
(\mathrm{~min})\end{array}$ & $f_{1}$ & $f_{2}$ \\
\hline Silymarin & 22.4 & - & - & 12.3 & - & - & 15. & - & - \\
\hline Kneading (1:1) & 18.3 & 60.2 & 30.0 & 13.7 & 60.1 & 29.4 & 17.4 & 32.5 & 39.9 \\
\hline Spray drying(1:3) & 11.4 & 118.5 & 18.0 & 16.2 & 96.1 & 19.3 & 14.4 & 75.5 & 22.1 \\
\hline Co-precipitates (1:3) & 7.8 & 169.4 & 10.2 & 7.4 & 128.7 & 13.2 & 8.3 & 91.4 & 17.4 \\
\hline Physical mixture (1:1) & 20.9 & 11.3 & 62.9 & 17.6 & 15.7 & 56.8 & 12.5 & 5.9 & 72.2 \\
\hline Physical mixture (1:3) & 21.5 & 12.6 & 61.4 & 19.2 & 4.5 & 57.8 & 13.4 & 6.2 & 72.2 \\
\hline
\end{tabular}

MDT - mean dissolution time.

$f_{1}, f_{2}-$ dissimilarity and similarity factor. 
D. Sonali et al.: Silymarin-solid dispersions: Characterization and influence of preparation methods on dissolution, Acta Pharm. 60 (2010) 427-443.

Table V. Drug content and dissolution parameters of co-precipitated solid dispersion during stability study

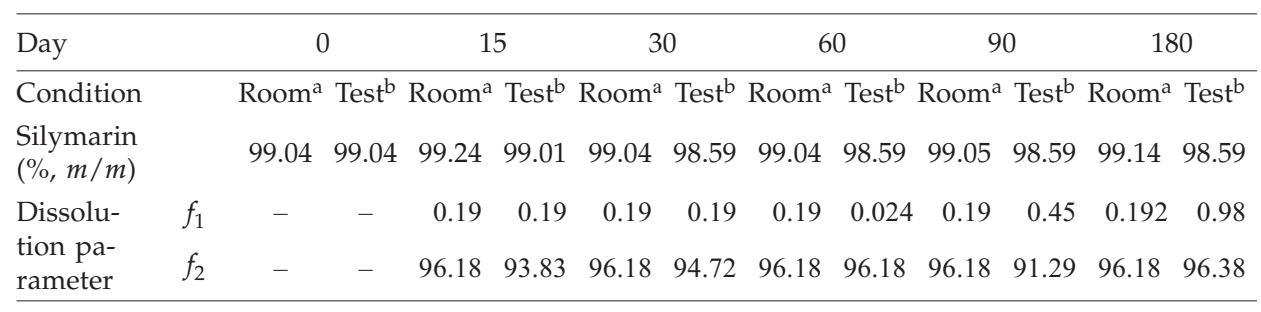

a $25 \pm 2{ }^{\circ} \mathrm{C}$ and $40 \pm 5 \% \mathrm{RH}$

b $40 \pm 2{ }^{\circ} \mathrm{C}$ and $75 \pm 5 \% \mathrm{RH}$

$f_{1}$ and $f_{2}$ - dissimilarity and similarity factor

\section{Stability}

The silymarin content in solid dispersions was higher than $98 \%(\mathrm{~m} / \mathrm{m})$ over a period of 15, 30, 60, 90 and 180 days and implies stability of prepared dispersions (Table $\mathrm{V})$. Difference in drug release between aged and freshly prepared dispersions was evaluated by similarity and dissimilarity factors $\left(f_{1}\right.$ and $\left.f_{2}\right)$. The results indicate similarity in the dissolution profile of dispersions over a period of 6 months.

\section{CONCLUSIONS}

In conclusion, preparation methodologies have an effect on the physicochemical characteristics of the dispersion and rate of dissolution of silymarin. Aqueous solubility of silymarin was favoured by the presence of HPMC 15LV and spontaneous drug solubilization was also confirmed by the negative value of Gibb's free energy. Among various drug to polymer ratios, the most favourable condition was found in 1:1 for the kneading method and 1:3 for other methods. The reduced intensity without shifting of characteristic peaks justifies weak hydrogen bond formation between the drug and polymer. The X-ray diffraction pattern clearly demonstrates reduction in crystallinity and formation of partial amorphism in dispersions prepared by kneading, spray drying or co-precipitation. SEM photographs also support the amorphism in solid dispersions. Preparation methodology clearly affects the dissolution parameters. Improvement in the rate of dissolution can be attributed to the increased surface area, increased solubility and reduction in crystallinity. The increased dissolution rate observed in the case of physical mixtures might be due to the close contact of HPMC with silymarin, which improves wetting and dissolution or might be caused by one or more of the characterization factors mentioned previously. Statistical evaluation suggested enhancement in silymarin dissolution in co-precipitation ( 2.5 fold) $>$ spray drying ( 1.9 fold $)>$ kneading ( 1.5 fold). Mean dissolution time (in $\mathrm{min}$ ) was as follows: 8.3 for co-precipitation, 14.2 for spray drying and 17.4 for kneading. 
D. Sonali et al:: Silymarin-solid dispersions: Characterization and influence of preparation methods on dissolution, Acta Pharm. 60 (2010) 427-443.

Acknowledgements. - We thank to Microlabs (India), Ltd. and Colorcon India, Ltd. for providing gratis samples.

\section{REFERENCES}

1. S. Ahmad and N. Dixit, Silymarin: a review of pharmacological aspects and bioavailability enhancement approach, Ind. J. Pharm. 39 (2007) 172-179; DOI: 10.4103/0253-7613.36534.

2. S. Abrol, T. Aman and K. O. Parkash, Comparative study of different silymarin formulations: formulation, characterization and in vitro/in vivo evaluation, Curr. Drug Deliv. 2 (2005) 45-51; DOI: $1567-2018 / 05 \$ 50.00+.00$.

3. P. D. Nakhat, R. A. Naidu, I. B. Babla, S. Khan and P. G. Yeole, Design and evaluation of silymarin-HP- $\beta$-CD solid dispersion tablets, J. Pharm. Sci. 69 (2007) 287-289; DOI: 10.4103/0250-474X.33160.

4. J. H. Hu and F. Q. Li, Improvement of the dissolution rate of silymarin by means of solid dispersions, Chem. Pharm. Bull. 52 (2004) 972-973; DOI: 10.1248/cpb.52.972.

5. S. W. Jong, T. S. Kim, J. H. Park, and S. C. Chi, Formulation and biopharmaceutical evaluation of silymarin using SMEDDS, Arch. Pharm. Res. 30 (2007) 82-89; DOI: 10.1007/BF02977782.

6. W. Wachter and H. Zeskae, Flavanolignan Preparation and their Use for Preparation of Pharmaceuticals, U.S. Pat. 5,906,991, 25 May 1999.

7. D. Voinovich, B. Perrisuiti and L. Maggaroto, Solid state mechanochemical simultaneous activation of the constituents of the Silybum marianum phytochemical complex with crosslinked polymers, J. Pharm. Sci. 3 (2008) 1-14; DOI: 10.1002/jps.21417.

8. J. B. Dressman and L. Christian, Improving drug solubility for oral delivery using solid dispersions, Eur. J. Pharm. BioPharm. 50 (2000) 47-60; DOI: 10.1016/S0939-6411(00)00076-X.

9. Y. Rane, R. Mashru, M. Sankalia and J. Sankalia, Effect of hydrophilic swellable polymers on dissolution enhancement of carbamazepine solid dispersions studied using response surface methodology, AAPS Pharm. Sci. Tech. 8 (2007) Article 27; DOI: 10.1208/pt0802027.

10. A. Avani and M. Renuka, Formulation development of taste-masked rapidly dissolving films of cetirizine hydrochloride, Pharm. Tech. 33 (2009) 48-56.

11. S. J. Hwang, D. H. Won, M. S. Kim, S. Lee and J. S. Park, Improved physicochemical characteristics of felodipine solid dispersion particles by supercritical anti-solvent precipitation process, Int. J. Pharm. 301 (2005) 199-208; DOI: 10.1016/j.ijpharm.2005.05.017.

12. United States Pharmacopoeia 24/National Formulary 19, USP Convention, Rockville 2000, p. 2235.

13. P. Costa and L. J. Manuel Sousa, Modelling and comparison of dissolution profiles, Eur. J. Pharm. Sci. 13 (2001) 123-133; DOI: 10.1016/S0928-0987(01)00095-1.

14. J. W. Moore and H. H. Flanner, Mathematical comparison of dissolution profiles, Pharm. Tech. 20 (1996) 64-74.

15. R. P. Patel and M. M. Patel, Solid-state characterization and dissolution properties of lovastatin hydroxypropyl-beta-cyclodextrin inclusion complex, Pharm. Tech. 2 (2007) 72-81.

16. S. Baboota, M. Dhalival and K. Kohli, Physicochemical characterization, in vitro dissolution behaviour, and pharmacodynamic studies of rofecoxib-cyclodextrin inclusion compounds: preparation and properties of rofecoxib hydroxypropyl $\beta$-cyclodextrin inclusion complex: a technical note, AAPS Pharm. Sci. Tech. 6 (2005) 83-90; DOI: 10.1208/pt060114.

17. M. A. Khan and A. A. Karnachi, Box-Behnken design for the optimization of formulation variables of indomethacin co-precipitates with polymer mixtures, Int. J. Pharm. 131 (1996) 9-17; DOI: 10.1016/0378-5173(95)04216-4. 
D. Sonali et al.: Silymarin-solid dispersions: Characterization and influence of preparation methods on dissolution, Acta Pharm. 60 (2010) 427-443.

18. S. Torrado, P. D. Torre and S. Torrado, Preparation, dissolution and characterization of pranziquantel solid dispersions, Chem. Pharm. Bull. 47 (1999) 1629-1633; DOI: 99A1042280.

19. S. R. Vikram, M. R. Shelake, S. S. Shetty, A. B. Chavan-Patil, Y. V. Pore and S. G. Late, Enhanced solubility and dissolution rate of lamotrigine by inclusion complexation and solid dispersion technique, J. Pharm. Pharm. Sci. 60 (2008) 1121-1129; DOI: 10.1211/jpp.60.9.0002.

20. K. Okimoto, M. Miyake, R. Ibuki, M. Yasumura, N. Ohnishi and T. Nakai, Dissolution mechanism and rate of solid dispersion particles of nilvadipine with hydroxypropylmethylcellulose, Int. J. Pharm. 159 (1997) 85-93; DOI: 10.1016/S0378-5173(97)00274-3.

21. M. S. Nagarsenker and M. S. Joshi, Celecoxib cyclodextrin systems: characterization and evaluation of in vitro and in vivo advantage, Drug Dev. Ind. Pharm. 31 (2005) 169-178; DOI: 10.1081/ DDC-200047795.

\section{Čvrste disperzije silimarina: Karakterizacija i utjecaj načina priprave na oslobađanje}

DALWADI SONALI, SONI TEJAL, THAKKAR VAISHALI i GANDHI TEJAL

U radu je ispitivan utjecaj načina priprave čvrstih disperzija silimarina na brzinu oslobađanja. Čvrste disperzije silimarina pripravljene su pomoću hidrofilnog polimera HPMC E 15LV metodom gnječenja, sušenja sprejom i koprecipitacijom. Pripravci su karakterizirani pomoću FTIR, DSC, XRPD i SEM. Profili oslobađanja uspoređivani su statistički i pomoću metoda koje su neovisne o modelu. FTIR i DSC studije otkrile su postojanje slabih vodikovih veza između lijeka i polimera, dok su XRPD i SEM potvrdile da je silimarin u čvrstim disperzijama amorfan. Poboljšano oslobađanje u odnosu na čisti lijek uočeno je ovim slijedom: koprecipitacija > sušenje sprejom $>$ metoda gnječenja $(p<0.05)$. Iz svih pripravaka oslobađanje je bilo sporije, bez obzira na metodu priprave. Pripravci dobiveni metodom koprecipitacije bili su stabilni, a oslobađanje silimarina iz njih bilo je 2,5 bolje u odnosu na čisti lijek.

Ključne riječi: silimarin, HPMC, čvrste disperzije, gnječenje, sušenje sprejom, koprecipitacija, parametri oslobađanja

Ramanbhai Patel College of Pharmacy, Charotar University of Science and Technology Changa-388421, India

Anand Pharmacy College, Anand-388001, India 